\title{
EDUCAÇÃO INFANTIL NO MUNICÍPIO DE TURVO : UM MAPEAMENTO DA OFERTA E DA ESTRUTURA DA REDE
}

Juceli Cândido ${ }^{1}$

\section{RESUMO}

Este artigo apresenta um estudo sobre a Educação Infantil no município de Turvo, estado de Santa Catarina. Partindo de um referencial teórico que examina as prerrogativas dos documentos legais, realizou-se uma pesquisa de campo que buscou investigar qual a oferta de Educação Infantil no município e como esta rede está estruturada em termos de gestão. Dados obtidos por meio do histórico da educação no município e de entrevista com gestores revelaram que o município conta com instituições públicas e privadas para atender as crianças em creches e pré-escolas e que a rede pública possui unidades na zona urbana e rural. Também existe uma equipe gestora multidisciplinar, que atua na Secretaria de Educação do município, dando suporte a todas as unidades de Educação Infantil da rede pública municipal.

Palavras chave: educação infantil; gestão; creche; pré-escola

\section{ABSTRACT}

This article presents a study on Early Childhood Education in the municipality of Turvo, state of Santa Catarina. Based on a theoretical framework that examines the prerogatives of legal documents, a field research was carried out that sought to investigate the offer of Early Childhood Education in the municipality and how this network is structured in terms of management. Data obtained through the history of education in the municipality and interview with education managers revealed that the municipality counts on public and private institutions to serve children of day care centers and preschools and that the public network has units in the urban and rural areas. There is also a multidisciplinary management team, which acts in the Department of Edcuation of the municipality, supporting all the units of Early Childhood Education of the municipal public network.

Key words: Childhood Education; management; day care; preschools.

\section{INTRODUÇÃO}

A Educação Infantil, primeira etapa da educação básica, tem seu processo de gestão no âmbito das redes municipais de ensino. Assim, considerando a obrigatoriedade de oferta da Educação Infantil nos municípios, bem como o direito de toda a criança, a partir de zero meses, de ter acesso à E.I., a organização da estrutura

\footnotetext{
1 Graduada em Pedagogia com Ênfase em Ensino Religioso pela PUC MINAS. Pós graduada em Educação Infantil e Séries Iniciais pela UNOPAR e pós graduada em gestão escolar pela UNESC; juceli.candido@gmail.com
} 
CRIAR EDUCAÇ̃̃O
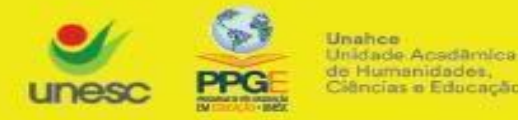
ediunesc

Criar Educação, Criciúma, v. 9, no2, Edição Especial 2020.- PPGE - UNESC - ISSN 2317-2452

municipal para atender alunos em creches e pré-escolas é um dos desafios que se apresentam aos governos municipais.

As condições da estrutura física, de pessoal, de materiais e de gestão de uma rede de Educação Infantil são decisivas para o êxito desta etapa da educação. Estudar esses contextos, portanto, poderá subsidiar os gestores nas decisões e possibilitar à sociedade um melhor acompanhamento desta oferta. Além disso, dados que expliquem este cenário contribuem para a construção de documentos que possam nortear a gestão da E.I. no município.

O presente trabalho pretende realizar um estudo da rede de Educação Infantil no município de Turvo-SC e, a partir da legislação atual, realizar um mapeamento desta rede, prioritariamente acerca das condições de oferta e do sistema de gestão. Para isso, trabalhamos com a seguinte questão de pesquisa: Qual a oferta de Educação Infantil no município de Turvo-SC e como esta rede está estruturada em termos de de gestão? Para responder a essa indagação, tivemos, como objetivo geral, conhecer a oferta e a estrutura da rede de Educação Infantil do município de Turvo. Especificamente, objetivamos conhecer e descrever a estrutura organizacional e de gestão da E.I. no município. A seguir, empreendemos análises dessa estrutura à luz da legislação vigente.

No que diz respeito aos procedimentos metodológicos do estudo, que resultou na elaboração deste artigo, foi realizada uma pesquisa bibliográfica, documental e de campo, com coleta de dados por meio de entrevistas e análise de documentos. Foram sujeitos da pesquisa a atual Secretária da Educação do município de Turvo - SC e outros membros da equipe de gestão das instituições de Educação Infantil do município.

Os critérios utilizados para a coleta de dados foram visitas à Secretaria de Educação e às instituições de Educação Infantil do município de Turvo - SC e entrevista direcionada à secretária de educação e membros da equipe diretiva da Secretaria Municipal de Educação. 


\section{REFERENCIAL TEÓRICO}

A Educação Infantil tem, hoje, um lugar assegurado no sistema educacional brasileiro, sendo reconhecida, na legislação, como primeira etapa da educação básica (BRASIL, 2009). Porém, não se pode deixar de considerar que, em um passado não muito distante, este espaço era ainda muito restrito, situando-se apenas no âmbito da assistência social, a exemplo do que acontecia também em outras partes do mundo.

Stemmer (2012, p. 06) lembra que "as instituições de educação infantil surgiram com um caráter meramente assistencialista", tendo a baixa qualidade de atendimento como uma das suas principais marcas. Assim, muitos aspectos precisam ser considerados quando o tema em pauta é a Educação Infantil, desde as questões sobre sua origem até a configuração alcançada pela atual legislação brasileira para regulamentar o atendimento das crianças de 0 a 6 anos.

A história da Educação Infantil no mundo e no Brasil está ligada diretamente ao surgimento do capitalismo, no século XIX, quando ocorreram grandes mudanças econômicas, sociais e culturais na sociedade, alterando também a estrutura familiar. A mulher, até então, era quem deveria permanecer no lar e cuidar dos filhos e do marido.

Com a nova realidade surgida a partir do avanço do capital, ela passa a assumir o trabalho assalariado, executando uma jornada de trabalho tão pesada quanto a do homem. Como consequência, surge um grande problema: onde deixar as crianças pequenas? A solução surge com as chamadas "mães mercenárias", mulheres que deixavam de ir para as fábricas e vendiam seus trabalhos para as mães operárias.

Estas cuidadoras não possuíam qualquer tipo de formação ou preparo para agruparem estas crianças, o que fez surgir verdadeiros depósitos de crianças de todas as idades. Partindo deste contexto de necessidade, surgem maneiras mais formais 

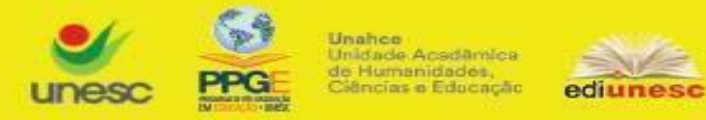

Criar Educação, Criciúma, v. 9, oㅡ2, Edição Especial 2020.- PPGE - UNESC - ISSN 2317-2452 de cuidado com crianças pequenas, com a consequente terceirização da educação dos filhos das operárias (STEMMER, 2012).

Após esta primeira fase conturbada pela qual passou a estruturação da Educação Infantil, houve a necessidade de um lugar no qual as mães pudessem deixar seus filhos pequenos, para irem trabalhar nas fábricas. Em decorrência destas novas ofertas, aparecem, aos poucos, inúmeras entidades filantrópicas, públicas e até mesmo particulares que buscam redimensionar a proposta de trabalho para as crianças de 0 a 6 anos (STEMMER, 2012).

A partir deste momento, a criança, que antes não possuía qualquer importância, passa a ser alvo de preocupação, buscando-se uma melhoria nas condições e espaços físicos destinados a ela. Surgem, em diferentes locais, novas tendências para o desenvolvimento desta atividade educacional. Ainda no século XIX, temos o primeiro jardim de infância, em meados de 1840, em Blankenburgo, na Alemanha, buscando melhor atender estas crianças, bem como suas famílias. No mesmo período, surgiram, no Brasil, entidades que pretendiam prestar este tipo de trabalho.

No caso brasileiro, este processo de implantação foi mais lento, pois somente nas primeiras décadas do século XX ocorreu o surgimento de creches e jardins de infância. Estas instituições possuíam dois grandes objetivos: cuidar das crianças pequenas e possibilitar um espaço adequado ao seu desenvolvimento.

No Brasil, a Educação Infantil levou longos anos para ser considerada como parte integrante do processo educacional. Esta fase do processo ensino aprendizagem era deixada de lado. O Estado, nesse contexto, desempenhava um papel assistencialista e não impedia uma configuração de estratificação social no seio da Educação Infantil. Sobre isso, o parecer do Conselho Nacional de Educação/Câmara de Educação Básica (Parecer CNE/CEB 20/2009), que apresenta as Diretrizes Curriculares Nacionais para a Educação Infantil, diz que: 


\section{4
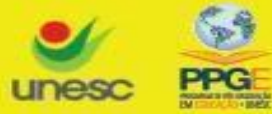 \\ Unahee

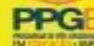 \\ Humaniogadorto \\ ediunese}

Criar Educação, Criciúma, v. 9, №2, Edição Especial 2020.- PPGE - UNESC - ISSN 2317-2452

a construção da identidade das creches e pré-escolas a partir do século XIX em nosso país insere-se no contexto da história das políticas de atendimento à infância, marcado por diferenciações em relação á classe social das crianças. Enquanto para as mais pobres essa história foi caracterizada pela vinculação aos órgãos de assistência social, para as crianças das classes mais abastadas, outro modelo se desenvolveu no diálogo com práticas escolares (BRASIL, 2009).

Somente entre os anos de 1970/1980 ocorreram mobilizações e preocupações neste sentido, como nos movimentos de luta pelos direitos das crianças por creches e no processo da Constituinte, a partir do que a E.I. deixa de ser vista somente como um local para o depósito de crianças, no qual as mães trabalhadoras poderiam deixar seus filhos pequenos, para comparecerem ao trabalho (RIZZO 2003).

Com a Constituição Federal (BRASIL, 1988), e especialmente a partir da década de 1990, ocorreu, no Brasil, uma real preocupação com a educação da primeira infância. Teve início, neste período, a elaboração de uma proposta mais eficaz para a Educação Infantil, traçando, assim, uma linha de trabalho, embora que ainda principiante.

Neste período, uma das mais importantes conquistas foi a elaboração e aprovação da nova Lei de Diretrizes e Bases da Educação Nacional - LDB, no ano de 1996. A partir deste marco, considerado um divisor de águas no processo educacional brasileiro, a E.I. conquista o direito de receber a devida valorização e mais recursos. A nova versão da LDB/96 especifica muito bem qual a função e a importância de todas as fases da educação no decorrer da vida de um indivíduo e inclui a Educação Infantil como "primeira etapa da Educação Básica" (BRASIL, 1996). Isso permitiu a compreensão de que o desenvolvimento da educação formal engloba toda a vivência escolar do sujeito, iniciando-se já na creche. No primeiro capítulo da LDB/96 lê-se:

Art. 1ㅇ A educação abrange os processos formativos que se desenvolvem na vida familiar, na convivência humana, no trabalho, nas instituições de ensino e pesquisa, nos movimentos sociais e organizações da sociedade civil e nas manifestações culturais.

$\S 1^{\circ}$ Esta lei disciplina a educação escolar, que se desenvolve, predominantemente, por meio do ensino, em instituições próprias.

$\S$ 2ํㅗ A educação escolar deverá vincular-se ao mundo do trabalho e à prática social. 

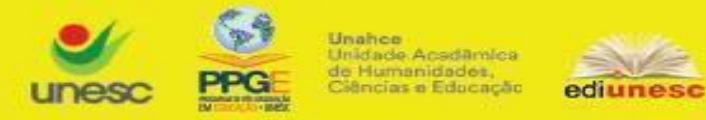

Criar Educação, Criciúma, v. 9, n²2, Edição Especial 2020.- PPGE - UNESC - ISSN 2317-2452

No artigo segundo, a nova LDB deixa evidente as origens da educação e qual o seu destino, qual a sua finalidade e, por fim, declara que todo indivíduo que nasce ou mora neste país tem o direito de receber uma educação de qualidade, e que o torne um cidadão conhecedor dos seus direitos e deveres. Afirma-se, então, que a qualificação para o trabalho, fonte de crescimento para nós e as futuras gerações, é fato importante e que deve receber atenção. Assim diz a Lei:

Art. $2^{\circ}$ A educação, dever da família e do Estado, inspirada nos princípios de liberdade e nos ideais de solidariedade humana, tem por finalidade o pleno desenvolvimento do educando, seu preparo para o exercício da cidadania e sua qualificação para o trabalho.

Mesmo com a aprovação da nova LDB/96, a Educação Básica, e nessa, principalmente a Educação Infantil no país, ainda possui um árduo caminho a percorrer. Atualmente, nos deparamos com inúmeras dificuldades em organizar, reorganizar e até mesmo desmistificar estas ideias, que fazem parte do nosso contexto histórico, social e cultural. Diferentes órgãos governamentais ligados diretamente à educação como o MEC (Ministério da Educação), a SEB (Secretaria de Educação Básica), entre outros, está buscando e oportunizando uma maior qualidade no desenvolvimento e na elaboração das propostas para a Educação Infantil em todo o país, levando em consideração as mais diferentes realidades aqui encontradas (KRAMER, 2011).

Segundo Kramer (1995, p. 30), "considera-se a educação como promotora da melhoria social. A proposta que ressurge é a de elaborar programas de educação préescolar a fim de transformar a sociedade do futuro" e, portanto, é através da educação que temos a oportunidade de promover mudanças sociais, seja de maneira ampla, seja no aspecto individual de promoção humana. Sendo a Educação Infantil integrante das etapas da educação básica, ela deve participar ativamente nesta proposta de mudança e desenvolvimento social.

Essas conquistas que a E.I. alcançou ao longo do tempo somente se consolidam caso vários aspectos sejam observados: estrutura física adequada às 
especificidades das crianças; formação docente direcionada para essa etapa da educação básica; organização curricular sólida, articulada com aspectos sociais, históricos e culturais; entre outros fatores. Tais elementos estão diretamente vinculados à estrutura de gestão da Educação Infantil no âmbito de cada rede.

Espera-se, na oferta da Educação Infantil, não somente o cuidado, mas o acompanhamento do desenvolvimento cognitivo, em todos os âmbitos, sejam eles psicológico, afetivo ou social. Em muitas situações, a creche ou a pré-escola tornamse apoio em relação à saúde física e emocional das crianças ainda tão pequenas. Também cabe ressaltar que, no dia a dia de muitos espaços dedicados à Educação Infantil, é quando estas crianças são higienizadas e alimentadas de maneira correta e necessária. Sendo assim, é imprescindível conhecer esse período escolar na vida e na sobrevivência de tantas crianças, principalmente em um pais como o Brasil, que possui inúmeras e diferentes realidades sociais, territoriais e culturais. Assim, Goldschmied e Jackson (2006) nos recordam:

Apesar dos grandes avanços em nosso conhecimento acerca de como um bebê se desenvolve desde antes do nascimento até a maturidade, neste país estamos ainda longe de dar sério reconhecimento à importância dos primeiros três anos (Goldschmied e Jackson, 2006, p. 13)

No que se refere ao espaço físico da escola que atende a criança de 0 a 06 anos, se faz necessário lembrarmos que nas teorias de grandes estudiosos do processo ensino aprendizagem como Vygotsky, Piaget, Montessori, Froebel e outros, podemos encontrar a preocupação com esse elemento. Os Referenciais Curriculares Nacionais para a Educação Infantil fazem menção contínua ao espaço físico escolar que irá atender essas crianças com a primeira etapa da vida escolar.

Tal preocupação é relevante, considerando quão importante é para o desenvolvimento da criança ainda pequena um espaço que a favoreça fazer experiências, ter contato com diferentes realidades, sentir-se mais segura e desafiada a fazer parte desse meio. Assim, nos Referenciais Curriculares Nacional para a Educação Infantil lemos: 


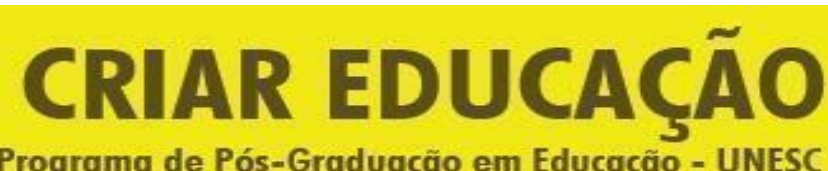

Revista do Programa de Pós-Graduação em Educação - UNESC

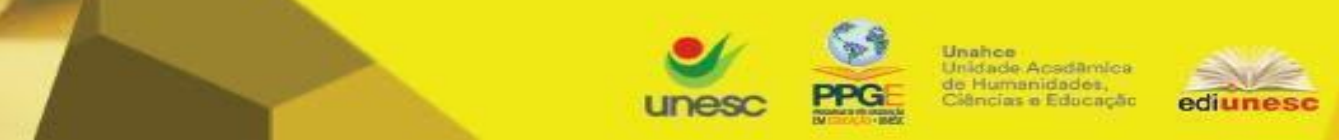

Criar Educação, Criciúma, v. 9, oㅡ, Edição Especial 2020.- PPGE - UNESC - ISSN 2317-2452

O espaço na instituição de educação infantil deve propiciar condições para que as crianças possam usufruí-lo em benefício do seu desenvolvimento e aprendizagem. Para tanto, é preciso que o espaço seja versátil e permeável à sua ação, sujeito às modificações propostas pelas crianças e pelos professores em função das ações desenvolvidas. Deve ser pensado e rearranjado, considerando as diferentes necessidades de cada faixa etária, assim como os diferentes projetos e atividades que estão sendo desenvolvidos. (BRASIL, 1998, p. 69)

O espaço adequado também influencia positivamente nas atividades de brincadeira das crianças. Sabe-se o quanto uma criança gosta e sente prazer na hora de brincar. Assim também, todos os teóricos e estudiosos da educação infantil concordam sobre a importância do brincar no desenvolvimento integral de cada ser humano. É na etapa da Educação Infantil, na qual a criança tem garantido por lei o direito de brincar e fazer experiências, que ela realiza seus maiores aprendizados, que a acompanharão por toda a vida. Assim lemos na nova LDB:

A Educação Infantil é conceituada como a primeira etapa da Educação Básica e tem como finalidade o desenvolvimento integral da criança até cinco anos de idade, em seus aspectos físico, psicológico, intelectual e social, complementando a ação da família e da comunidade. (LDB, lei 9394/96, Art.29)

É através do brincar que a criança inicia seu processo de experiência do mundo externo, possibilitando começar o seu processo de construção de visão de mundo, e de tudo o que está a sua volta. O brincar também favorece o desenvolvimento físico e cognitivo, como das próprias emoções e sentimentos. O campo da dicção e do raciocínio também sofrem mudanças através do brincar. Outro aspecto muito importante na hora da brincadeira é a possibilidade que cada criança tem de aumentar o número de palavras que consegue falar ou de apropriar-se do conhecimento do sentido e do significado.

A brincadeira, seja ela dirigida ou livre, faz com que a criança faça a experiência e aprenda a respeitar as regras e, principalmente, inicia seu processo de desenvolvimento da ética como do sentimento de perder ou ganhar. Assim os PCNs nos dizem que: 


\section{4
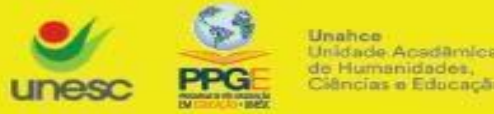

Criar Educação, Criciúma, v. 9, №2, Edição Especial 2020.- PPGE - UNESC - ISSN 2317-2452

O fato de a criança, desde muito cedo, poder se comunicar por meio de gestos, sons e mais tarde representar determinado papel na brincadeira faz com que ela desenvolva sua imaginação. Nas brincadeiras as crianças podem desenvolver algumas capacidades importantes, tais como a atenção, a imitação, a memória, a imaginação. Amadurecem também algumas capacidades de socialização, por meio da interação e da utilização e experimentação de regras e papéis sociais (BRASIL, 1998, p. 22).

Também o currículo para a Educação Infantil é fator fundamental para o desenvolvimento da criança nessa etapa da educação. Para falarmos de currículo na E.I. no Brasil, e portanto em qualquer município, devemos tomar como base as novas Diretrizes Curriculares Nacionais para a Educação Infantil (BRASIL, 2009). Estas foram elaboradas buscando suprir as novas e urgentes necessidades educacionais em todo território nacional. Para elaboração do DCNEls, buscou-se levar em consideração o que, há muito tempo, profissionais e estudiosos da área educacional vinham discutindo e estudando.

A principal função dos DCNEls é aquela de instrumentalizar o professor de Educação Infantil para que ele possa estruturar e organizar as atividades educativas e pedagógicas do dia a dia, da sua turma e, consequentemente, de toda a instituição educativa, buscando formas de integração dinâmica entre as realidades do âmbito escolar e social, ambas de suma importância no decorrer de todo o processo ensino aprendizagem. Assim, as DCNEls, em seus objetivos gerais, nos apresentam a função sociopolítica e pedagógica das instituições de educação infantil:

a. Oferecer condições e recursos para que as crianças usufruam seus direitos civis, humanos e sociais;

b. Assumir a responsabilidade de compartilhar e complementar a educação e cuidado das crianças com as famílias;

c. Possibilitar tanto a convivência entre crianças e entre adultos e crianças quanto à ampliação de saberes e conhecimentos de diferentes naturezas;

d. Promover a igualdade de oportunidades educacionais entre as crianças de diferentes classes sociais no que se refere ao acesso a bens culturais e às possibilidades de vivência da infância;

e. Construir novas formas de sociabilidade e de subjetividade comprometidas com a ludicidade, a democracia, a sustentabilidade do planeta e com o rompimento de relações de dominação etária, socioeconômica, étnico-racial, de gênero, regional, linguística e religiosa (BRASIL, 2009).

Portanto, temos objetivos claros, que definem muito bem a função e a importância desta etapa na trajetória de vida escolar de cada criança. Quando esta 


\section{(1)
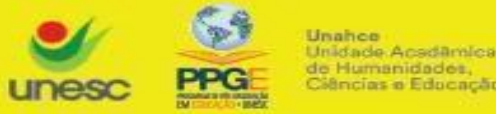

Criar Educação, Criciúma, v. 9, №2, Edição Especial 2020.- PPGE - UNESC - ISSN 2317-2452

etapa não é bem desenvolvida, quando o profissional não possui clareza do seu papel, em todo este processo, podem ocorrer inúmeras dificuldades, sendo elas em âmbito cognitivo, psicológico e até mesmo emocional. Assim, temos a necessidade de articular teoria e prática, escola e família, espaço escolar e espaço social, e isso somente pode ocorrer quando existem linhas traçadas com clareza. Por isso, as DCNEls nos propõem:

o currículo da Educação Infantil é concebido como um conjunto de práticas que buscam articular as experiências e os saberes das crianças com os conhecimentos que fazem parte do patrimônio cultural, artístico, ambiental, científico e tecnológico, de modo a promover o desenvolvimento integral de crianças de 0 a 5 anos de idade (BRASIL, DCNEI, 2009, art. $3^{\circ}$ )

E principalmente nos afirma que o centro de todo o processo, é a criança, ou seja, ela é o sujeito. E novamente o documento afirma:

As propostas pedagógicas da Educação Infantil deverão considerar que a criança, centro do planejamento curricular, é sujeito histórico e de direitos que, nas interações, relações e práticas cotidianas que vivencia, constrói sua identidade pessoal e coletiva, brinca, imagina, fantasia, deseja, aprende, observa, experimenta, narra, questiona e constrói sentidos sobre a natureza e a sociedade, produzindo cultura (BRASIL, DCNEI, 2009, art. 4º).

Em todo esse processo que configura a etapa da Educação Infantil, no qual estão reunidos aspectos como espaço físico, possibilidade de desenvolvimento de atividades de brincadeira pertinentes à faixa etária atendida, currículo adequado, é fundamental o papel da gestão. É essa que articula recursos, equipe e normativas que poderão dar forma à essa etapa da vida escolar da criança. Assim, apesar de haver legislação vigente específica que disciplina e orienta as ações no campo da Educação Infantil, de nada adiantará o amparo legal se as redes não estiverem estruturadas para efetivar as ações e isso está na dependência direta da gestão.

Esse trabalho, levando em conta todos os aspectos mencionados anteriormente, buscou conhecer uma rede municipal para compreender como as Diretrizes e pressupostos teóricos acerca da E.I. se materializam, na prática.

\section{A EDUCAÇÃO INFANTIL NO MUNICÍPIO DE TURVO - SC: RESULTADOS DE CAMPO}



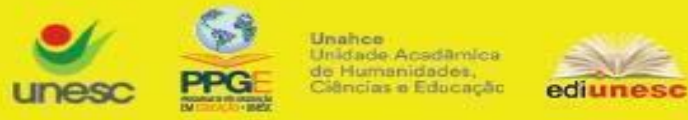

Criar Educação, Criciúma, v. 9, n²2, Edição Especial 2020.- PPGE - UNESC - ISSN 2317-2452

Posteriormente à esta iniciativa da professora Virgínia, surge a necessidade de buscar recursos para a educação, que, nos relatos históricos, revela-se como um processo longo, no qual as conquistas por mais escolas e mais professores preparados exigiu um trabalho árduo e demorado.

Inicia-se, então a instalação, no município, de escolas municipais e estaduais referentes ao ensino fundamental. Em cada comunidade do município foram construídas escolas isoladas, que atendiam as crianças oferecendo apenas da primeira até a quarta série. Isso ocorria em turmas multisseriadas, nas quais a mesma professora trabalhava com duas séries ao mesmo tempo, sendo esta também responsável por toda a documentação dos alunos, limpeza do espaço escolar e merenda, o que as faziam verdadeiras heroínas da educação.

Quem desejasse ou até mesmo tivesse possibilidade de dar continuidade aos estudos tinha que se dirigir à área urbana do município, onde seria possível cursar o antigo ginásio, que correspondia ao período da quinta série à oitava série.

A sede do município contava com duas dependências escolares. A primeira foi a escola de Educação Básica Jorge Schultz, fundada no ano de 1925, tendo como primeira professora Virginia Cechinel, uma desbravadora em relação à educação formal em Turvo.

Após muitos anos, ocorreu a implantação da segunda escola, no ano de 1962, denominada por todos como escola Estadual, sendo que mais tarde recebeu o nome de Escola de Educação Básica João Colodel. Neste estabelecimento escolar, pretendia-se atender aos alunos da quinta a oitava série, porém, na época, devido às exigências do MEC, o grande problema, bem maior que a falta de recursos financeiros, era a falta de professores formados adequadamente para ministrarem as aulas.

Sendo assim, enquanto ocorria construção do prédio, três professores que já desenvolviam suas atividades como regentes de turmas, foram enviados à cidade de Passo Fundo, para se prepararem e adquirirem os certificados necessários para ministrar aulas na nova escola. A partir deste momento, os alunos turvenses, oriundos 
CRIAR EDUCAÇ̃̃O

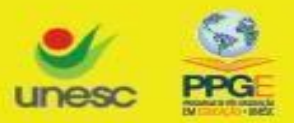

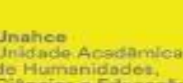

Criar Educação, Criciúma, v. 9, no2, Edição Especial 2020.- PPGE - UNESC - ISSN 2317-2452

tanto da área urbana como rural do município, podiam contar com duas escolas.

Apenas no ano de 1971, em parceria com mais dois municípios vizinhos, houve a implantação de uma escola para atender aos alunos com o curso que, na época, era denominado Segundo Grau. Esta escola, denominada Colégio Servos de Maria, começou suas atividades escolares no ano de 1972 e recebeu este nome por ser um colégio pertencente à Ordem Religiosa dos Servos de Maria, sendo de caráter particular. Após sua abertura, o colégio não teve só influência no âmbito educacional da região, mas passou a ser referência em relação às atividades esportivas.

A Educação Infantil do município de Turvo teve, como primeira escola dedicada a esta etapa, a Casa da Criança, que mais tarde passou a ser conhecida por "Centro Educacional Casa da Criança”. Conforme apontado pela Diretora da instituição, essa escola tem como finalidade da sua proposta educacional buscar o desenvolvimento integral da criança, entendendo que este é o caminho para que se tenha, futuramente, homens e mulheres capazes de reconhecer o valor da própria existência, bem como da existência do outro.

Esta escola foi implantada no município no ano de 1962, pelas Irmãs Sacramentinas de Bergamo, com o total apoio, na época, tanto do poder público quanto da população, que buscava para suas crianças uma educação de qualidade no âmbito cognitivo, com fundamentos religiosos. Assim, o Centro Educacional Casa da Criança desenvolve seu trabalho de educar e formar os cidadãos turvenses a mais de cinco décadas.

Este foi o início da trajetória da educação no município, que atualmente conta com um sistema educacional composto por 10 escolas de ensino fundamental, sendo 04 estaduais e 05 da rede municipais e 01 da rede particular. A Educação Infantil no município de Turvo - SC, atualmente, é atendida por dois segmentos: seguimento municipal, e o segmento particular. As escolas particulares situam-se na zona urbana, enquanto que as escolas do segmento público municipal localizam-se tanto na zona urbana quanto na zona rural. 
CRIAR EDUCAÇ̃̃O
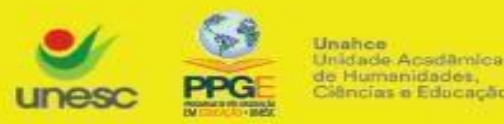

ediunesc

Criar Educação, Criciúma, v. 9, no2, Edição Especial 2020.- PPGE - UNESC - ISSN 2317-2452

No que se refere à rede pública, a pesquisa revelou que essa encontra-se atualmente em processo de construção e ampliação da rede e tem passado por mudanças periódicas, as quais buscam promover melhorias e suprir as necessidades que os habitantes apresentam em relação a esta fase da educação e do desenvolvimento da criança, bem como atender a direitos garantidos por lei.

Segundo informações da Secretaria Municipal de Educação, o município oferece às crianças com idade de 0 a 5 (cinco) anos e 11 (onze) meses o serviço de creche e pré-escola, tanto na área urbana como na rural. Na área rural, a rede pública municipal de ensino atende 50 (cinquenta) alunos de pré-escolar e 6 (seis) alunos de creche. Já na área urbana, o número de atendimentos dá um salto, havendo a matrícula de 191 (cento e noventa e um) alunos na etapa de pré-escolar e 303 (trezentos e três) alunos na etapa de creche.

O município de Turvo- SC conta com uma rede de educação estruturada a partir de um núcleo gestor, que é a Secretaria Municipal de Educação. Nesse núcleo, está centralizada a gestão de todas as etapas da educação básica atendidas pelo município, ou seja, Educação Infantil e Ensino Fundamental. A Secretaria de Educação possui uma equipe gestora assim constituída: secretária municipal de educação, responsável pelo órgão e pelo controle de todos os processos burocráticos, pela implantação de programas, pelo recebimento de demandas da sociedade referentes à educação, entre outros; 01 (uma) orientadora educacional, 01 (uma) supervisora pedagógica e 01 (uma) psicóloga, as quais atuam em demandas específicas dessas áreas e que se originam nas várias escolas da rede.

Conforme informações obtidas na Secretaria Municipal durante esta pesquisa, a equipe da SME trabalha com todas as possibilidades existentes e disponíveis, buscando firmar parcerias, por exemplo, com a Secretaria da Saúde, o Centro de Referência e Assistência Social - CRAS e o Conselho Tutelar.

Em relação à Educação Infantil, a rede pública municipal de educação está organizada conforme mostra o quadro 1. 


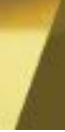

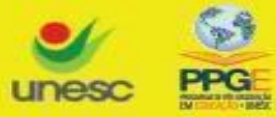 \\ Unahoe \\ unesc \\ PPG \\ ediunesc}

Criar Educação, Criciúma, v. 9, №2, Edição Especial 2020.- PPGE - UNESC - ISSN 2317-2452

Quadro 01: Síntese da rede municipal de Educação Infantil de Turvo - SC

\begin{tabular}{|c|c|c|}
\hline Localização & Tipo de unidade escolar & No \\
\hline \multirow{3}{*}{ Área rural } & creche e pré-escola & 01 \\
\cline { 2 - 3 } & Ensino fundamental (anos iniciais) e pré-escola & 01 \\
\cline { 2 - 3 } & $\begin{array}{c}\text { Ensino fundamental (anos iniciais e finais ) e pré- } \\
\text { escola }\end{array}$ & 01 \\
\hline \multirow{2}{*}{ Área urbana } & creche & 02 \\
\cline { 2 - 3 } & pré-escola & 02 \\
\cline { 2 - 3 } & Creche e pré-escola & 01 \\
\hline
\end{tabular}

Fonte: elaborado pela autora, a partir de dados de pesquisa de campo

$\mathrm{Na}$ área urbana não existe a coexistência de ensino fundamental e educação infantil na mesma unidade escolar. Segundo informações obtidas na SME, isso assim se organiza devido ao maior número de alunos na Educação Infantil, o que faz com que as dependências das escolas urbanas se tornem pequenas para atender a todos os alunos. No total, Turvo conta, então, com oito unidades escolares dedicadas à E.I., sendo cinco urbanas e 3 rurais. Destas unidades, apenas uma não possui direção própria e está localizada na área rural do município.

Em relação à rede particular, as escolas de Educação Infantil particulares do município estão localizadas na área urbana, mas não deixam de atender crianças da área rural e também dos municípios vizinhos como Ermo e Meleiro. No que se refere ao espaço físico, as creches localizadas no município de Turvo buscam favorecer o melhor possível as necessidades das crianças que atende.

Os espaços das oito unidades dedicadas a esta etapa escolar foram adaptados ou construídos visando a proporcionar um ambiente que seja favorável a possibilitar à criança o êxito no seu processo de aprendizagem e desenvolvimento. Existe estrutura para atender às prerrogativas da E.I. especialmente no que se refere à interação, brincadeira e participação. Esses espaços, no município, estão organizados de maneira a permitir ao professor a execução da sua ação educativa e formativa de 


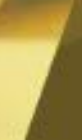

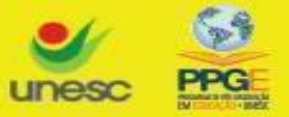 \\ Unahoe \\ unesc}

Criar Educação, Criciúma, v. 9, no22, Edição Especial 2020.- PPGE - UNESC - ISSN 2317-2452

maneira competente e agradável. As famílias também se fazem presentes em várias atividades, buscando estar o mais próximo possível.

\section{CONSIDERAÇÕES FINAIS}

Este trabalho, que buscou conhecer a rede de Educação Infantil em Turvo-SC, evidenciou que o município tem uma rede estruturada em termos de estrutura física e pedagógica. Há um núcleo gestor situado na Secretaria Municipal de Educação, com equipe pedagógica e administrativa multidisciplinar. Essa equipe gerencia uma rede que distribui-se no município, abrangendo inclusive a área rural. Cada unidade de Educação Infantil possui, no local, uma direção, que está articulada com a equipe da Secretaria Municipal.

Esse modelo de gestão, que abriga uma equipe pedagógica multidisciplinar, associado a uma rede que se estrutura com base em adequados ambientes escolares e profissionais capacitados, atende às prerrogativas das Diretrizes Curriculares Nacionais para a Educação Infantil e permite um trabalho voltado para o desenvolvimento infantil de forma integral, nos aspectos biopsicossociais e na formação da autonomia da criança.

Cabe ressaltar que, observando o histórico da Educação em Turvo, a Educação Infantil não surge com os primórdios do processo de educação no município, mas instala-se posteriormente e permanece até hoje, oferecendo educação desde a fase de creche. Também cabe salientar que a rede de E.I. de Turvo oferece creche na zona rural, fato que é escasso no cenário brasileiro, uma vez que a zona urbana é mais privilegiada na oferta de atendimento de bebês de 0 a 2 anos.

\section{REFERÊNCIAS BIBLIOGRÁFICAS}

BRASIL. Constituição de 1988. Constituição da República Federativa do Brasil. 
CRIAR EDUCACÃ̃O

Criar Educação, Criciúma, v. 9, n²2, Edição Especial 2020.- PPGE - UNESC - ISSN 2317-2452

Brasília, Senado Federal, 1988.

BRASIL. Ministério da Educação. Conselho Federal de Educação. Câmara de Educação Básica. Diretrizes Curriculares Nacionais para a Educação Infantil. Parecer homologado pelo despacho do Ministro, publicado no D.O.U. de 9/12/2009á, Seção 1, p. 14.

Lei oㅜ 9394, de 20 de dezembro de 1996. Lei de Diretrizes e Bases da Educação Nacional. Brasília, 1996.

Ministério da Educação. Secretaria de Educação Continuada, Alfabetização, Diversidade e Inclusão. Secretaria de Educação Profissional e Tecnológica. Conselho Nacional de Educação. Câmara Nacional de Educação Básica. Diretrizes Curriculares Nacionais Gerais da Educação Básica. Brasília. MEC, SEB, 2013.

GOLDSCHMIED, Elinor; JACKSON, Sonia. Educação de $\mathbf{0}$ a $\mathbf{3}$ anos: 0 atendimento em creche. 2. ed., Porto Alegre: Artmed, 2006.

KRAMER, Sonia. A política do pré-escolar no Brasil: a arte do disfarce. 5. ed. São Paulo: Cortez,1995.

RIZZO, Gilda. Creche: organização, currículo, montagem e funcionamento. 3. ed. Rio de Janeiro: Bertrand Brasil, 2003.

Recebido abril de 2019 Aprovado junho de 2020 